\title{
Relationship between the ratio of villous height:crypt depth and gut bacteria counts as well production parameters in broiler chickens
}

\author{
Dung T. N. Nguyen ${ }^{1 *}$, Ngoc H. Le ${ }^{1}$, Vinh V. Pham ${ }^{2}$, Parra Eva $^{3}$, \\ Forti Alberto ${ }^{3}$, \& Hien T. Le ${ }^{1}$ \\ ${ }^{1}$ Faculty of Animal Science and Veterinary Medicine, Nong Lam University, Ho Chi Minh City, Vietnam \\ ${ }^{2}$ Animaid Ltd, Vietnam \\ ${ }^{3}$ Ascor-Vetoquinol, Italia
}

\author{
ARTICLE INFO \\ Research Paper \\ Received: March 08, 2021 \\ Revised: May 13, 2021 \\ Accepted: May 24, 2021
}

\section{Keywords}

Broilers

Crypt depth

Gut health

Meat quality

Villous height

\section{*Corresponding author}

Nguyen Thi Ngoc Dung

Email: dungnguyenngoc2004@gmail.com

\begin{abstract}
The villous height to crypt depth $(\mathrm{V}: \mathrm{C})$ ratio is one of the most significant parameters which is associated with the nutrients' absorption and greater body weight. The objective of this study was to assess the relationship between $\mathrm{V}: \mathrm{C}$ ratio, gut bacteria counts and production parameters in broiler chickens. A total of 100 individual broilers were randomly selected from a farm with 40,000 Ross 308 chickens and slaughtered for sampling at three different ages including 14, 28 and 37 day old. Villous height and crypt depth were measured for each section of the small intestine to calculate $\mathrm{V}$ : C ratio. Intestinal score and gut microbiology including total coliforms, lactic acid bacteria and Salmonella prevalence were assessed. At day 37, besides those parameters, the carcass, breast, legs and wings were taken for weight measurements. Leg and breast color was also measured. Data were statistically analyzed by STATA software to explore the relationship between V:C and those parameters. The results showed the positive correlation between $\mathrm{V}: \mathrm{C}$ of duodenum and the number of lactic acid bacteria at 28 days of age $(P<0.05)$. Moreover, the leg yield was negatively related to the $\mathrm{V}: \mathrm{C}$ ratio of jejunum $(P<0.05)$. No significant correlations were found between $\mathrm{V}: \mathrm{C}$ ratio and other parameters. The results indicated the potential of controlling $\mathrm{V}: \mathrm{C}$ ratio to improve gut health and meat quality of broiler chickens and thus, further studies should be conducted to fully evaluate these correlations.
\end{abstract}

Cited as: Nguyen, D. T. N., Le, N. H., Pham, V. V., Eva, P., Alberto, F., \& Le, H. T. (2021). Relationship between the ratio of villous height:crypt depth and gut bacteria counts as well production parameters in broiler chickens. The Journal of Agriculture and Development 20(3), 1-10.

\section{Introduction}

The poultry sector is one of the most rapidly growing food-producing animal industries worldwide. A primary emphasis of the commercial broiler industry has been to maximize the growth, meat yield and quality of birds while maintaining their health at an optimal level. The small intestine is a vital organ that is the major site for digestion and absorption of nutrients which is related to growth performance. The chickens'gut health provides broad implications for their systemic health and the correlation between animal performance and gut health is universally accepted. The definition of gut health contains microbiology, immunology, morphology and physiology of the intestinal tract. Because a part of the digestive and also all of the absorptive capac- 
ity of the small intestine occur around and near villi and crypts, it is well-known that the villus height:crypt depth ratio is the gut health index (Pluske, 1996).

At hatch, the gastrointestinal tract of broilers is completely undeveloped, affecting the ability of the animal to digest and absorb nutrients. There are drastic changes in the first few days of age in physiological characteristics, such as expression of membrane transporters, endogenous enzyme activities and cell differentiation, and physical characteristics, including villus and crypt development and the size of the digestive tract (Uni et al., 2001). The growth of intestinal villus length is correlated to the enhanced digestive and absorptive functions of the intestine, leading to an increase in total luminal villus absorptive area and an increased activity among intestinal brush border enzymes (Prakatur et al., 2019). While the decrease in the crypt depth achieves an increase in the enzymatic activity of the small intestine which affects to absorption ability (Kelly et al., 1991). In addition, a higher ratio between villous height and crypt depth leads to a slower maintenance requirement and consequently, reaches a higher growth efficiency of the animal as a result of a decreased turnover of the intestinal mucosa (Van Nevel et al., 2005).

In literature, there are only a few studies that have previously described the identified influence of chickens' histological feature changes on the growth of poultry and gut microbiota, but rarely on meat quality. Additionally, in Vietnam, the investigations with regards to these relationships have not been carried out yet. In the strategy of antibiotic alternatives, several products such as probiotics, prebiotics and phytochemicals were proven that had positive impacts on $\mathrm{V}: \mathrm{C}$ ratio. According to Awad et al. (2009), the supplementation of either synbiotic or probiotic reveals the improvement in the villus height:crypt depth ratio and villus height in both duodenum and ileum. Demir et al. (2003) indicated that there was a reduction in crypt depth in the ileum of broilers given dietary natural growth promoters such as garlic. Therefore, the specific objectives of the present study were to reveal the relationship between the ratio of villus height to crypt depth and other parameters related to chicken performance, gut microbiota and meat quality in the field condition which has become the foundation for this strategy.

\section{Materials and Methods}

\subsection{Animals}

Broiler chickens were collected from a commercial farm in Vung Tau province. A total of 40000 day-old Ross 308 broiler chickens of the farm were housed in 2 buildings with a dimesion of $15 \mathrm{~m} \mathrm{x}$ $100 \mathrm{~m}$ and $6 \mathrm{~m}$ height, and equipped with 212 feeders and 382 drinkers (approximately 95 birds per feeder and 52 birds per drinker) for each. Temperature, humidity, and lighting in the facility were maintained according to the manufacturer's recommendations for the Ross 308 hybrid (Aviagen, 2018). Chickens were raised from dayold to 37 days (ready for slaughter) and provided with water as well as diet ad libitum. Feed used for broiler was from Kyodo Sojitz and the size of feed was changed based on the age of animals (Table 1). Feed had correctly small size and contained high level of probiotic with the purpose support digestive function for baby chicken. From 1 to 14 days, pellet of feed should be $1.5-3.0 \mathrm{~mm}$ diameter, $1.5-3.0 \mathrm{~mm}$ length, while it should be $3.0-4.0 \mathrm{~mm}$ in diameter, $4.0-7.0 \mathrm{~mm}$ in length and a change in texture as well as nutrition composition at grower period (15 - 21 days). From 22 days to finish, the birds were fed with pellet which should be $3.0-4.0 \mathrm{~mm}$ in diameter, 5.0 8.0 in length. Breeding was conducted on straw (5 cm depth) and lasted for more than 5 weeks (37 days).

Table 1. Nutritional compositions of feed at three different stages

\begin{tabular}{cccc}
\hline Compositions & \multicolumn{3}{c}{ Stage } \\
\cline { 2 - 4 } & Starter & Grower & Finisher \\
\hline $\begin{array}{c}\text { Crude protein } \\
(\%)\end{array}$ & 21 & 19.5 & 19 \\
$\begin{array}{c}\text { Metabolizable } \\
\text { energy } \\
(\mathrm{kcal} / \mathrm{kg})\end{array}$ & 3000 & 3100 & 3150 \\
\hline
\end{tabular}

2.2. Sample collection, measurements, and
analysis

A total of 100 birds, 30 birds at 14 and 28 days of age and 40 birds at 37 days of age was randomly selected and tranported by car from farm to the lab of Nong Lam University HCMC. These points of time were representative for the three stages of development: starter (not fully devel- 
oped), grower (developing) and finisher (developed). Feed should be removed from the flock $12 \mathrm{~h}$ before the expected time of processing to reduce the risk of fecal contamination. Chickens were transported in the hostile temperature and given a 2-hour rest before slaughtering to minimize stress for chickens which can cause a huge impact on results. Before bleeding, birds were weighed to record their live weight. After that, birds were quickly scalded at $54^{\circ} \mathrm{C}$, defeathered in a rotary drum picker and manually eviscerated. This was a normal slaughter process and did not effect to the intestinal microbiota and morphology.

\subsubsection{Intestinal histomorphology}

Three segments of about $5 \mathrm{~cm}$ removed from the small intestine (duodenum, jejunum and ileum) were at the following locations: (i) the middle part of the duodenal loop, (ii) midpoint between the endpoint of the duodenal loop and Meckel's diverticulum (jejunum) and (iii) midway between the Meckel's diverticulum and the ileocaecal junction (Choe et al., 2012). The ingesta in the lumen washed away using normal saline and fixed in $10 \%$ buffered formalin. Then, all intestinal portions were dehydrated in an increasing series of ethanol, cleared in xylene, embedded in paraffin block and then cut into $5 \mu \mathrm{m}$ sections. After drying, paraffin-embedded sections that were stained with hematoxylin and eosin $(\mathrm{H} \& \mathrm{E})$ and examined under a light microscope (Olympus CX40). The procedure was a modified method from HairBejo (1990), as described by Thanh et al. (2009). A computer morphometric program, Optika Vision Pro 3.0, was used for morphometric measuring the villi height and crypt depth. The villus height was measured from the tip to the base of the villus and crypt depth was measured from the base of the villus to the mucosa. For each section, averaged height and depth measurements of 10 randomly selected villi and crypts were expressed. The ratio of villus to crypt was estimated by dividing the villus height by the crypt depth.

\subsubsection{Microbiology}

The ceca were dissected and the content was extracted into $50 \mathrm{~mL}$ sterilized falcon conical tubes for subsequent analysis of the bacterial populations by serial dilution. Microbiological pa- rameters included total coliforms, Salmonella and lactic acid bacteria. Total coliforms were isolated from cecal feces by multiple tube fermentation in lauryl tryptone broth (LTB) and brilliant green bile broth (BGBB) and enumerated by most-probable-number (MPN) estimated by using standard techniques. Salmonella was isolated by standard microbiological methods and was confirmed by biochemical and slide agglutination tests using commercial polyvalent O. Lactic acid bacteria were isolated on Lactobacillus agar DE Man, ROGOSA and SHARPE (MRSagar) plates and then, incubated under anaerobic conditions at $37^{\circ} \mathrm{C}$ for $48 \mathrm{~h}$. Samples were diluted in saline and chosen at least three continuous dilutions $\left(10^{-4}, 10^{-5}, 10^{-6}\right)$ to spread 0.1 $\mathrm{mL}$ samples directly onto the surface of MRSagar plates. Each dilution was repeated in duplicate. All colony forming units (CFU) on selected plates were counted and recorded. The number of colonies from 30 to 300 were accepted. All morphologies of colonies were observed including the shape and color, then selected to perform gramstain and observed under microscope to confirm.

\subsubsection{Intestinal scores}

All internal organs of slaughtered chickens were observed and recorded any abnormal lesions. Intestinal lesion scores were classified into 4 scales from 0 to 3 corresponding from normal to multifocal hemorrhage in intestinal tract (Table 2).

Table 2. Clinical scoring of intestines

\begin{tabular}{cl}
\hline Score Description \\
\hline 0 & $\begin{array}{l}\text { Normal, no hemorrhage, normal content } \\
1\end{array}$ \\
Focal hemorrhage (petechial hemor- \\
rhage) in a part of intestinal tract \\
2 & $\begin{array}{l}\text { More hemorrhage and/or hemorrhage } \\
\text { and swollen lymphoid patches }\end{array}$ \\
3 & $\begin{array}{l}\text { Multifocal hemorrhage in large area of } \\
\text { the intestinal tract, as well as in lym- } \\
\text { phoid patches and/or gas in lumen }\end{array}$ \\
\hline
\end{tabular}

\subsubsection{Carcass traits}

At 37 days, carcass and meat qualities were evaluated. After defeathering, eviscerating and removal of the head and paws, carcass weight was determined. The breast, wings, legs muscles of each birds were dissected and weighed. Carcass yield $(\mathrm{CY})$ corresponded to the ratio between 
carcass weight $(\mathrm{CW})$ and body weight at slaughter $(\mathrm{BW})$, and was calculated according to the following formula: CY $(\%)=\mathrm{CW} / \mathrm{BW} \times 100$. Parts yield (breast, wings and legs) was calculated as the ratio between the part weight and carcass weight, according to the formula: Part yield $(\%)=\mathrm{PY} / \mathrm{CW} \times 100(\mathrm{PY}$ is the representative value of each part). Breast and leg colors were also assessed by DSM broiler color fan which is expressed in a 101 - 110 scale corresponding from white to marigold color (Figure 1).

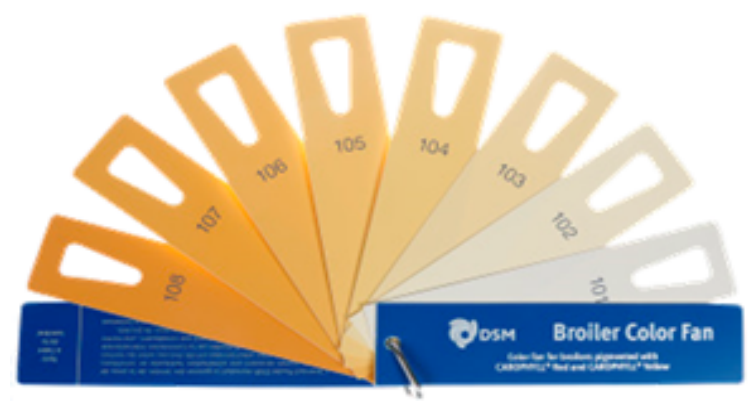

Figure 1. DSM broiler color fan.

\subsubsection{Meat quality parameters}

Drip loss and $\mathrm{pH}$ measurements were performed on the major pectoralis muscle of broiler breast. Breast muscles were removed by severing the humeral-scapular joint and pulling downward to strip the meat from the breast. After excision, the ultimate $\mathrm{pH}$ and drip loss evaluation were measured. The $\mathrm{pH}$ was assessed directly by inserting the probe of portable meat $\mathrm{pH}$ meter HI99163 in the same points in the breast at three different points of time including after $0 \mathrm{~h}, 4 \mathrm{~h}$ and $8 \mathrm{~h}$ post-mortem. All samples were keep at room temperature. Drip loss was measured using the filter paper press method (Kauffman et al., 1986), which evaluated the amount of moisture loss from the surface of the breast shortly after cutting ( $15 \mathrm{~min}, 4 \mathrm{~h}$ and $8 \mathrm{~h}$ ). The size of sample for drip loss measurement was approximately 10 g.

\subsection{Statistical analysis}

Data collected from the study were entered into Microsoft Excel (2016). For each measured parameter, basic descriptive statistics would be performed for undestanding its distribution to use as either a continuous or categorical variable.
The interested outcome variable was $\mathrm{V}$ : C ratio a continuous variable. The relationship between this one with other parameters (dependent variables) would be explored by certain methods. In particular, the one between $\mathrm{V}: \mathrm{C}$ ratio and dependent variables (intestinal score, $\log$ Coliforms, $\log \mathrm{LAB}, \mathrm{BW}$, carcass, breast, wing, leg yield, breast and leg color) would be assessed by correlation coefficient $(\mathrm{R})$ and slope coefficient of Univariate linear regression. With categorical variable (Salmonella prevalence), the mean of $\mathrm{V}: \mathrm{C}$ ratio of each category would be calculated and one-way ANOVA would be used to compare the difference of the means. The $P$ value less than 0.05 would be considered statistical significance. All analysis would be performed on STATA 14.2 software (College Station, Texas 77845 USA).

\section{Results}

\subsection{Evaluation of the relationship between the $\mathrm{V}: \mathrm{C}$ ratio and gut health}

The relationships among $\mathrm{V}: \mathrm{C}$ ratio and gut health were presented in three tables. At the age of 14 , no significant correlation was detected $(P$ $>0.05)$ (Table 3), while the positive correlation was found between $\mathrm{V}: \mathrm{C}$ ratio of duodenum and the number of lactic acid bacteria at the day of 28 (Fig 2). This relationship was statistically significant $(P<0.05)$ (Table 4$)$. It meant that the greater $\mathrm{V}: \mathrm{C}$ ratio, the higher number of lactic acid bacteria. At 37 days, the correlation between $\mathrm{V}$ :C ratio of ileum and intestinal score was significantly positive $(P<0.05)$ (Table 5$)$. The increased V:C ratio could result in the increase in intestinal score.
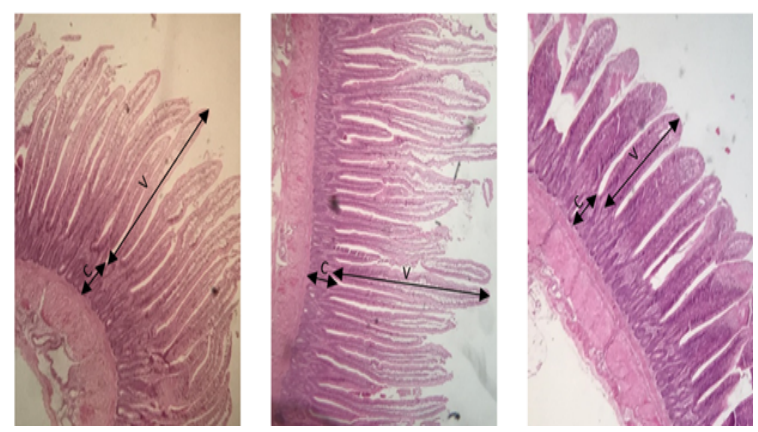

Figure 2. The representative histomorphometry of duodenum, jejunum and ileum (in order from left to right) at 28 days of age ( $\mathrm{V}$ : villous height, $\mathrm{C}$ : crypt depth) (x40). 

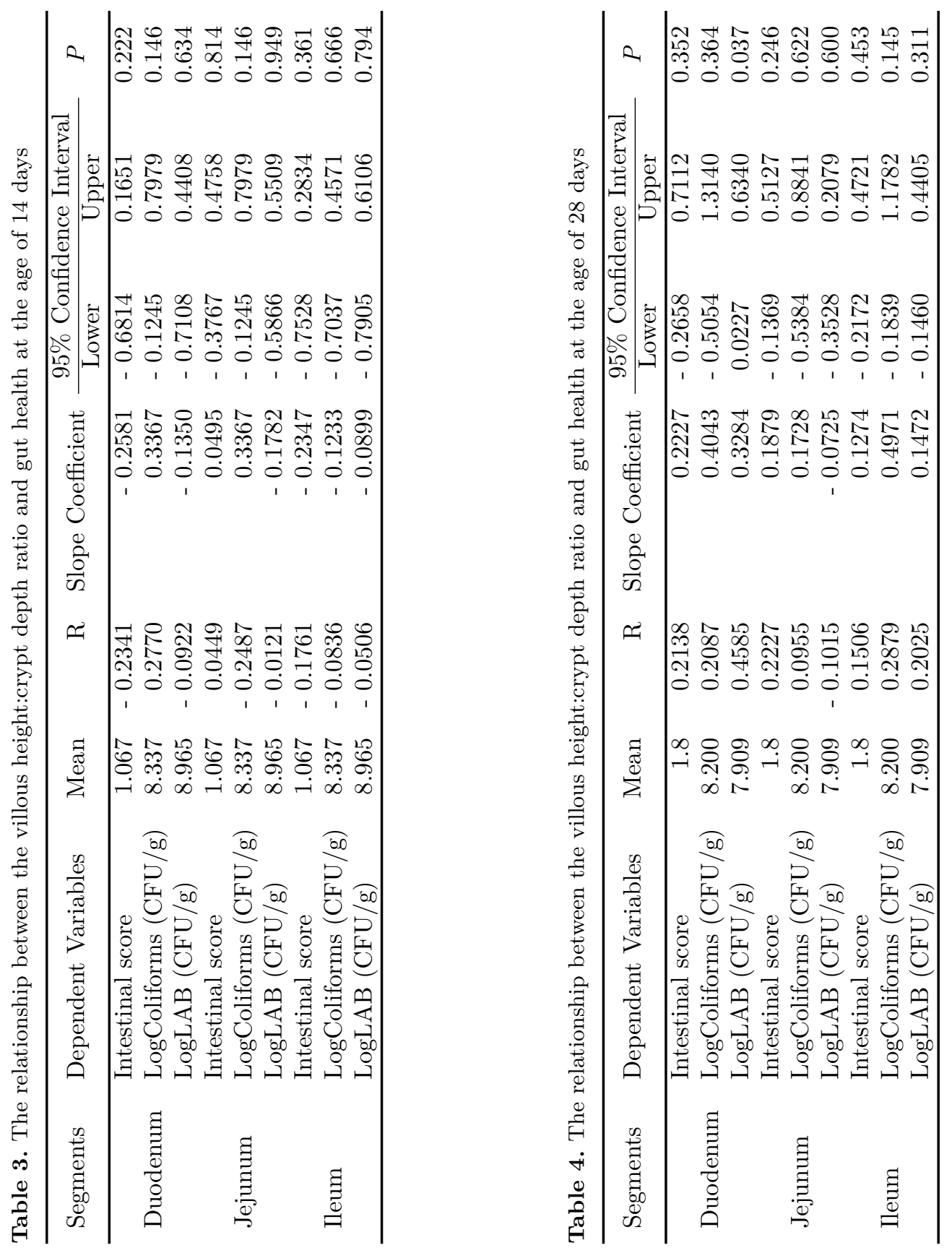

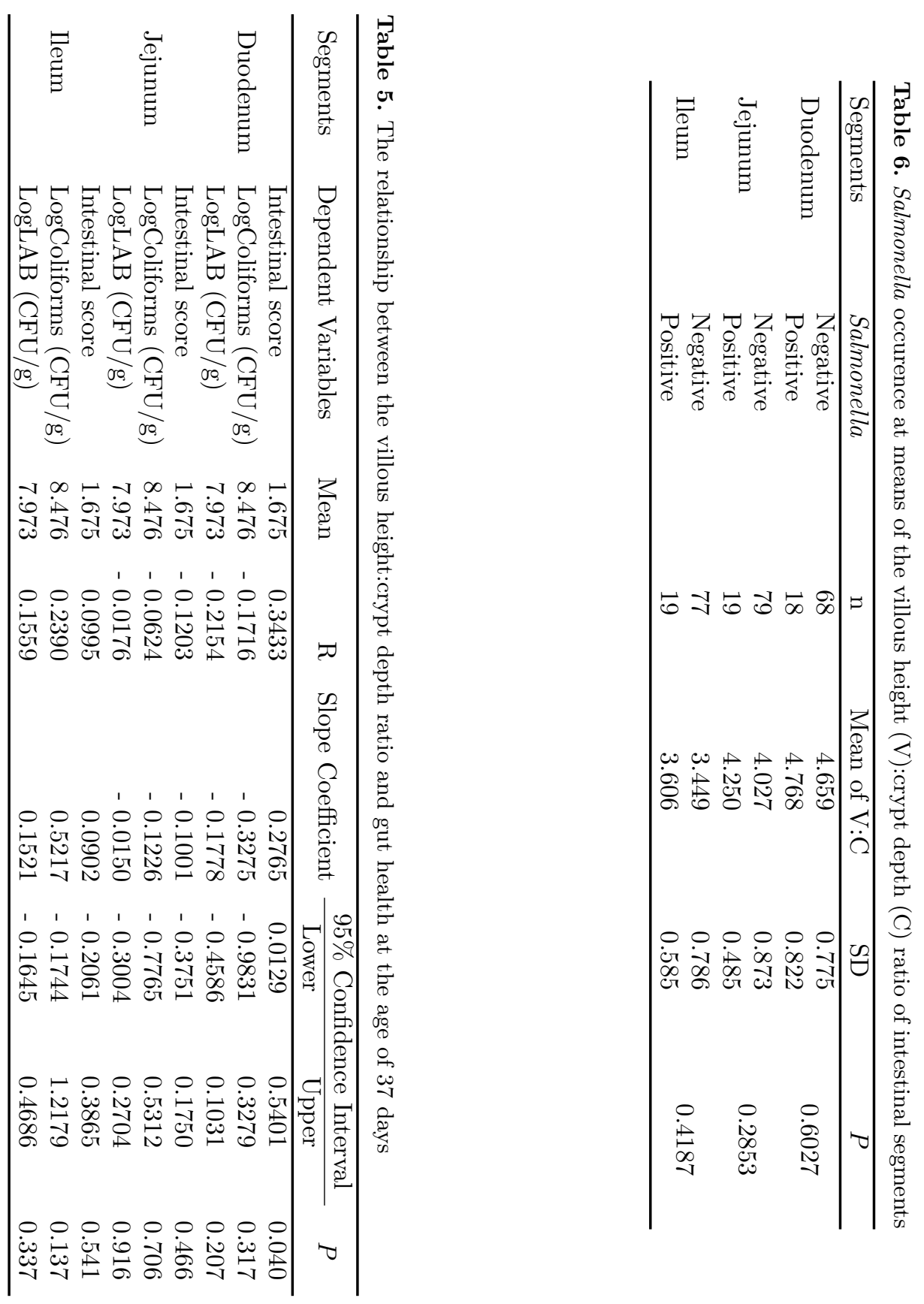


\subsection{Evaluation of the relationship between the V:C ratio and Salmonella occurence}

In this study, there was no significant correlation between V:C ratio and Salmonella occurence $(P>0.05$; Table 6$)$.

\subsection{Evaluation of the relationship between the V:C ratio, carcass yield and meat quality}

The leg and breast color did not show any correlations with $\mathrm{V}: \mathrm{C}$ ratio in all three sections of small intestines $(P>0.05$; Table 7$)$. Carcass, breast and wing weight had no correlation with $\mathrm{V}: \mathrm{C}$ ratio in three sections of small intestine. While leg weight was negatively related to the $\mathrm{V}: \mathrm{C}$ ratio of jejunum $(P<0.05)$, which indicated that the proportion of leg weight and carcass weight decreased $1.13 \%$ due to one-unit increased in jejunum $\mathrm{V}: \mathrm{C}$ ratio. No significant correlation among $\mathrm{V}: \mathrm{C}$ ratio, $\mathrm{pH}$ and drip loss.

\section{Discussion}

Intestine morphology may be mediated via alteration of intestinal microbiota. Based on the results of this study, the improvement of intestinal histomorphometry had a significant correlation with gut microbiota such as lactic acid bacteria. Previous studies have been reported that lactic acid bacteria could affect to intestinal histomorphometry (Chichlowski et al., 2007). According to Liao et al. (2020), the Lactobacillus was positively correlated with $\mathrm{V}: \mathrm{C}$ ratio in the ileum of the growing broilers which is consistent with the results of this study at the day of 28 $(P<0.05)$. The LAB supplement increased the $\mathrm{V}: \mathrm{C}$ ratio, thereby positively affecting the development morphology of the small intestine in the study of Gāliņa et al. (2020).

The relative increase in the percentage of the carcass could be related to gut health as well. The improvement in digestion and absorption efficiency of different nutritional materials due to the development of intestinal morphometry, consequently, leads to the improvement in carcass characteristics of broiler chickens (Hosseini et al., 2017). The results of this study did not found any correlation between $\mathrm{V}: \mathrm{C}$ ratio and carcass yields, except the negative association between $\mathrm{V}: \mathrm{C}$ ratio of the jejunum and leg yield $(P<$ $0.05)$. Moreover, the wing and leg yields in this study had negative relationship as well, while the breast yield was positive relationship . This finding could be considered as the increase in carcass quality. Despite the small sample size, these findings probably indicated that the improvement in carcass quality may result from the development of the gastrointestinal tract.

Some useful parameters for evaluating quality and consumer acceptability such as $\mathrm{pH}$ and drip loss can be affected by the supplementation of antioxidants such as vitamin E, selenium. The association between muscle vitamin $\mathrm{E}$ and lower drip loss has been described (Ashgar et al., 1991) and also a trend toward higher muscle $\mathrm{pH}$ at 24 h postmortem (5.7 vs. 5.5) (Lu et al., 2014). Although there is no further information about the relationship among the $\mathrm{V}: \mathrm{C}$ ratio, $\mathrm{pH}$ and drip loss, those coefficient seem to be at the direction of improvement of meat quality (higher $\mathrm{pH}(P$ $=0.051)$ and reduction of drip loss in the duodenum and ileum). Thus it can be thought that the higher $\mathrm{V}: \mathrm{C}$ ratio, the greater absorption of antioxidants supplied in the diet which probably impacts on meat quality.

Furthermore, the number of previous studies specified that the main compound with coloring function in meat and eggs is the carotenoids (Blanch \& Hernandez, 2000). Carotenoids are essential for the immune system, have antioxidant effects and cannot be synthesized by poultry that therefore needs to obtain these compounds from the diet (Kim et al., 2012). The skin color may be related to the absorption of carotenoids of chicken intestines. According to Lloyd (1970), most of the absorption of xanthophylls (one of the forms of carotenoids) takes place in the area of the jejunum-ileum in which E. maxima infections occur and very little xanthophylls are absorbed in the duodenum, ceca, and large intestine. Nevertheless, there were no significantly positive correlations between skin color and intestinal histomorphometry in this study.

It has been proven that shorter intestinal villi relative to crypt depth are related to a smaller number of absorptive cells and a larger number of secretory cells which are responsible for the secretion of mucins. Mucin is the major constituent of the mucous layer (Iwashita et al., 2003) which is the first line of the host intestinal defense and influences nutrient digestion and absorption. Under normal physiological conditions, mucin secretion is necessary to replenish and maintain a suitable 


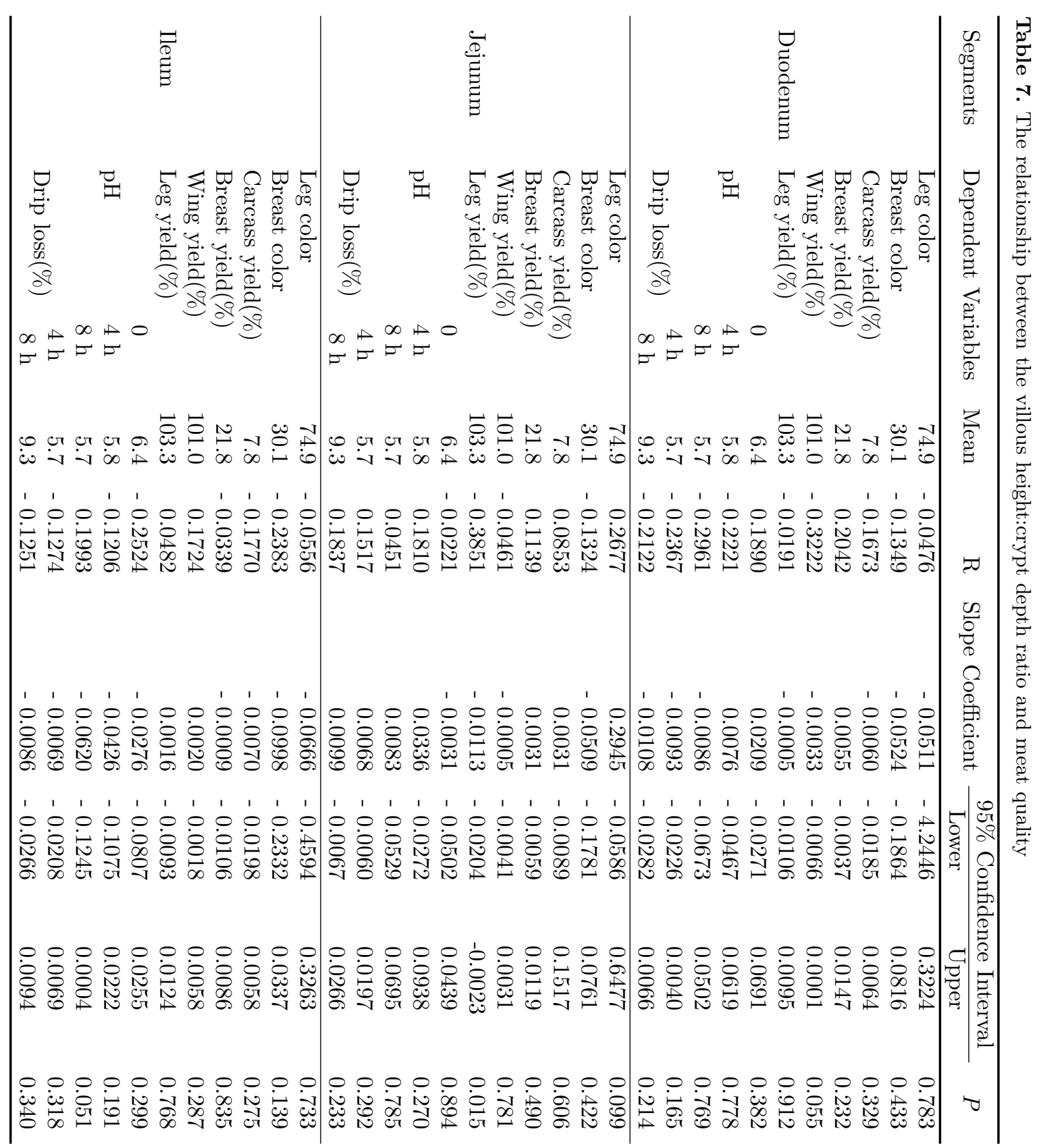


thickness of the mucous layer in the intestine because this layer is often sloughed off by intestinal movement, chemical compounds and microbially derived factors (Horn et al., 2009) to maintain gut health. Nevertheless, in this study, at the age of 37 day old, the greater the duodenum V:C ratio, the higher the intestinal lesion scores. This is not the desired finding but we believed that in the case of enteritis problems, the use of $\mathrm{V}: \mathrm{C}$ value should be concerned in the case of without antibiotics in feed.

\section{Conclusions}

The results achieved from the study showed that the significantly positive correlations among the $\mathrm{V}$ :C ratio, the number of lactic acid bacteria, intestinal scores and the negative one between $\mathrm{V}: \mathrm{C}$ ratio and the leg yield. No significant relationships between the $\mathrm{V}: \mathrm{C}$ ratio and other parameters were found. In conclusion, the promising and encouraging results of this study emphasize the importance of the further evaluation of the relationship between the intestinal morphology and other parameters in order to maximize the gut health of chickens and, consequently, the overall health of broiler chickens in the field condition.

\section{Acknowledgements}

The authors would like to express their deep gratitude to Animaid Company and AscorVetoquinol Company for funding for this study. This work was supported by the staff of the laboratory of Infectious Diseases and Veterinary Public Health Department for sample processing.

\section{References}

Ashgar, A., Gray, J. I., Miller, E. R., Ku, P. K., Booren, A. M., \& Buckley, D. J. (1991). Influence of supranutritional vitamin E supplementation in the feed on swine growth, performance and deposition in different tissues. Journal of Science of Food and Agriculture 57(1), 19-29.

Aviagen. (2018). Ross broiler management handbook. Retrieved December 22, 2018, from https://en.aviagen.com/assets/Tech_Center/Ross_Bro iler/Ross-BroilerHandbook2018-EN.pdf.

Awad, W. A., Ghareeb, K., Abdel-Raheem, S., \& Bohm, J. (2009). Effects of dietary inclusion of probiotic and synbiotic on growth performance, organ weights, and intestinal histomorphology of broiler chickens. Poultry Science 88(1), 49-56.
Blanch, A., \& Hernandez, J. M. (2000). Red carotenoids for optimal yolk pigmentation. Feed Mix 8(6), 9-12.

Chichlowski, M., Croom, W. J., Edens, F. W., McBride, B. W., Qiu, R., Chiang, C. C., Daniel, L. R., Havenstein, G. B., \& Koci, M. D. (2007). Microarchitecture and spatial relationship between bacteria and ileal, cecal and colonic epithelium in chicks fed a direct-fed microbial, Primalac, and Salinomycin. Poultry Science 86(6), 1121-1132.

Choe, D. W., Loh, Dr T. C., Foo, H. L., Hair-Bejo, M., \& Awis, Q. S. (2012). Egg production, faecal pH and microbial population, small intestine morphology, and plasma and yolk cholesterol in laying hens given liquid metabolites produced by Lactobacillus plantarum strains. British Poultry Science 53(1), 106-115.

Demir, E., Sarica, S., Ozcan, M. A., \& Suicmez, M. (2003). The use of natural feed additives as alternatives for an antibiotic growth promoter in broiler diet. British Poultry Science 44(1), 44-45. Gāliņa, D., Ansonska, L., \& Valdovska, A. (2020). Effect of probiotics and herbal products on intestinal histomorphological and immunological development in piglets. Veterinary Medicine International 2020, 3461768.

Hairbejo, M. (1990). Gastrointestinal response to copper excess, studies on copper (and zinc) loaded rats (Unpublished doctoral dissertion). University of Liverpool, Liverpool, United Kingdom.

Horn, N. L., Donkin, S. S., Applegate, T. J., \& Adeola, O. (2009). Intestinal mucin dynamics, response of broiler chicks and white pekin ducklings to dietary threonine. Poultry Science 88(9), 1906-1914.

Hosseini, S., Chamani, M., Seidavi, A., Sadeghi, A. A., \& Ansari-Pirsaraei, Z. (2017). Effect of feeding Thymolina ${ }^{\circledR}$ powder on the carcass characteristics and morphology of small intestine in ross 308 broiler chickens. Acta Scientiarum Animal Sciences 39(1), 45-50.

Iwashita, J., Yukita, S., Hiroko, S., Nagatomo, T., Hiroshi, S., \& Tatsuya, A. (2003). mRNA of MUC2 is stimulated by IL-4, IL-13 or TNF- $\alpha$ through a mitogen-activated protein kinase pathway in human colon cancer cells. Immunology and Cell Biology 81(4), 275-282.

Kauffman, R. G., Eikelenboom, G., Van der Wal, P .G., Merkus, G., \& Zaar, M. (1986). The use of filter paper to estimate drip loss of porcine musculature. Meat Science 18(3), 191-200.

Kelly, D., Smyth, J. A., \& McCracken, K. J. (1991). Digestive development of the early-weaned pig. 1. Effect of continuous nutrient supply on the development of the digestive tract and on changes in digestive enzyme activity during the first week post-weaning. British Journal of Nutrition 65(2), 169-180.

Kim, J. E., Clark, R. M., Park, Y., Lee, J., \& Fernandez, M. L. (2012). Lutein decreases oxidative stress and inflammation in liver and eyes of guinea pigs fed a hypercholesterolemic diet. Nutrition Research Practice 6(2), 113-119. 
Liao, X., Shao, Y., Sun, G., Yang, Y., Zhang, L., Guo, Y., Luo, X., \& Lu, L. (2020). The relationship among gut microbiota, short-chain fatty acids, and intestinal morphology of growing and healthy broilers. Poultry Science 99(11), 5883-5895.

Lloyd, H. L. (1970). The site of absorption of xanthophylls and factors affecting pigmentation of chickens, egg yolks, and products made from egg yolks (Unpublished doctoral dissertion). University of Tennessee, Knoxville, United States.

Lu, T., Harper, A. F., Scheffler, J. M., Corl, B. A., Estenne, M. J., \& Zhao, J. (2014). Supplementing antioxidants to pigs fed diets high in oxidants: II. Effects on carcass characteristics, meat quality, and fatty acid profile. Journal of Animal Science 92(12), 5464-5475.

Pluske, J. R., Tompson, M. J., Atwood, C. S., Bird, P. H., Williams, I. H., \& Hartmann, P. E. (1996). Maintenance of villus height and crypt depth, and enhancement of disaccharide digestion and monosaccharide absorption, in piglets fed on cow's whole milk after weaning. British Journal of Nutrition 76(3), 409-422.

Prakatur, I., Miškulin, M., Pavic, M., Marjanovic, K., Blazicevic, V., Miskulin, I., \& Domacinovic, M. (2019). Intestinal morphology in broiler chickens supplemented with propolis and bee pollen. Animals $9(6), 301$.
Thanh, N. T., Loh, T. C., Foo, H. L., Hair-Bejo, M., \& Azhar, B. K. (2009). Effects of feeding metabolite combinations produced by Lactobacillus plantarumon growth performance, faecal microbial population, small intestine villus height and faecal volatile fatty acids in broilers. British Poultry Science 50(3), 298306.

Uni, Z., Gal-Garber, O., Geyra, A., Sklan, D., \& Yahav, S. (2001). Change in the growth and function of chick small intestine epithelium due to early thermal conditioning. Poultry Science 80(4), 438-445.

Van Nevel, C. J., Decuypere, J. A., Dierick, N. A., \& Molly, K. (2005). Incorporation of galactomannans in the diet of newly weaned piglets, effect on bacteriological and some morphological characteristics of the small intestine. Archives of Animal Nutrition 59(2), 123-138. 